\title{
Heterochromatin Protein 1
}

National Cancer Institute

\section{Source}

National Cancer Institute. Heterochromatin Protein 1. NCI Thesaurus. Code C121992.

A protein family comprised of chromo and chromo shadow domain-containing, methyllysine binding proteins that are localized to heterochromatin. These proteins are involved in gene silencing, transcriptional activation, and the formation and stabilization of heterochromatin. 